\title{
Learning through crisis: development and implementation of a health cluster strategy for internally displaced persons
}

K.M. Bile, ${ }^{7}$ A.F. Shadoul, ${ }^{1}$ H. Raaijmakers, ${ }^{1}$ S. Altaf ${ }^{2}$ and K. Shabib ${ }^{3}$

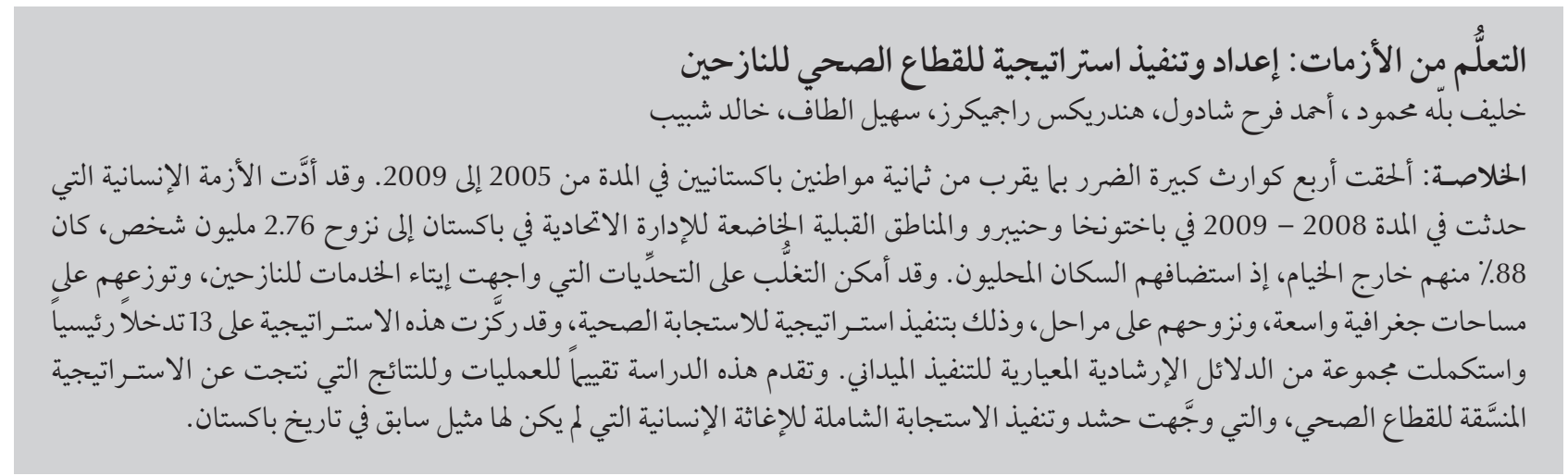

ABSTRACT Five major disasters in Pakistan affected close to 8 million people from 2005 to 2009. The 2008-09 humanitarian crisis in Khyber Pakhtunkhwa and the Federally Administered Tribal Areas (FATA) of Pakistan resulted in 2.76 million internally displaced persons (IDPs), of whom 88\% were off-camp IDPs hosted by the local population. The service delivery challenges posed by the IDPs, their sparse geographical distribution and phased displacement were managed through a successful health response strategy, which focused on 13 major interventions supplemented by a set of standard guidelines for field implementation. This study evaluates the process and results attained by this coordinated health cluster strategy that has guided the mobilization and implementation of a colossal humanitarian response to an unprecedented crisis in Pakistan's history.

Apprendre grâce à la crise : élaboration et mise en œuvre d'une stratégie de groupe Santé en faveur des personnes déplacées

RÉSUMÉ Au Pakistan, près de huit millions de personnes ont été frappées par quatre catastrophes majeures entre 2005 et 2009. En 2008-2009, la crise humanitaire qui a touché Khyber Pakhtunkhwa et les zones tribales sous administration fédérale du Pakistan ont fait 2,76 millions de personnes déplacées, dont 88 \% se trouvent hors des camps et sont hébergées par la population locale. En termes de prestations de services, les problèmes posés par les personnes déplacées, leur dispersion géographique et leurs déplacements par étapes ont été gérés grâce à une stratégie de riposte sanitaire couronnée de succès, comprenant treize interventions principales et un ensemble de directives standard de mise en œuvre sur le terrain. Cette étude évalue les processus et les résultats obtenus grâce à cette stratégie de groupe Santé coordonnée, qui a guidé la mobilisation et la mise en œuvre d'une impressionnante riposte humanitaire à une crise sans précédent dans I'histoire du Pakistan. 


\section{Introduction}

Humanitarian disasters are an increasingly common global challenge, in addressing which World Health Assembly Resolution 58.1 of 2005 stipulated the scope of health action in crisis. The World Health Organization (WHO) focuses on rapid situation and needs assessment, the coordination of health response interventions, identifying and filling critical gaps and revitalizing the capacity of a country's health system for preparedness and response. The resolution requested Member States to integrate risk reduction in health sector development interventions, apply risk mapping in order to reflect the role and importance of public health infrastructure, to pay particular attention to mental health needs and gender-based violence, to improve national mechanisms for emergency health response and to enhance financial contributions to generate sufficient capacity at the national level [1].

Valuable experience was gained from the five disasters which affected Pakistan since 2005: the 2005 earthquake in northern Pakistan, the 2006 cyclone and floods which affected 14 districts in the provinces of Balochistan and Sindh, the 2007 earthquake in the Balochistan districts ofZiarat and Pishin and the 2008-09 crisis in the Federally Administered Tribal Areas and Khyber Pakhtunkhwa (formerly North-West Frontier Province), which resulted in 2.6 million internally displaced persons (IDPs) [2-4] who were forced to flee their homes but remained within their country's borders.

The Health Cluster approach is a strategy developed to organize and coordinate cooperation among humanitarian actors and build partnerships in planning and response during disasters. This approach, first tested on a large scale in Pakistan during the 2005 earthquake, has generated successful outcomes, prompting its nationwide application for managing humanitarian disasters and complex emergencies $[5,6]$. During the IDP crisis (2008-09), WHO jointly assumed with the government the health response coordination role. The Organization was able to mobilize and position, at short notice, competent professional teams and critical health technologies and assume the role as the provider of last resort in the emergency health response $[6,7]$. To generate a unity of purpose among health cluster partners and improve the quality and effectiveness of response interventions for the IDPs, a health cluster strategy was developed. This article aims to illustrate the components of this jointly formulated strategy and exhibit its influence on the nationwide access to quality and life-saving services.

\section{Methods}

The emergency health response functions stipulated in the Global Health Cluster Guide and the country-level harmonized roles of different humanitarian clusters, collectively steered by the UN Office for Coordinating Humanitarian Affairs (OCHA), were the basis of the health cluster strategy [6]. The participatory strategy-design consultations carried out by the health cluster, the health response operational needs reflected by the assessment teams and the published literature, including the WHA resolutions on the subject, were reviewed.

\section{Results}

The Khyber Pakhtunkhwa and Federally Administered Tribal Areas humanitarian crisis of 2008-09 displaced 2.76 million people, creating a massive need for humanitarian action. The IDPs moved to safer and protected districts with $12 \%$ settled in camps and $88 \%$ hosted by local communities, reflecting the generosity and compassion expressed by the general population. On an average, a hosting family adopted 1.3 families in their home and offered all affordable basic needs to their vulnerable guests.

Figure 1 shows the humanitarian health response coordination framework. The health cluster and the national health sector authorities worked closely together, while collaboratively interfacing with other members of the humanitarian country team (HCT) and the numerous clusters engaged in different humanitarian response domains.

Figure 2 illustrates the total number of displaced families and returnees by area of origin from August 2008 to March 2010 upon restoration of security in their home towns and villages.

Figure 3 illustrates the crisis-affected areas, the routes of the IDPs' migration and the hosting districts in which they temporarily sought sanctuary. The dislodgment of the IDPs occurred in separate waves. IDPs from Swat and Buner shifted in July and August 2009, while the displacement from South Waziristan commenced later when the majority of IDPs from Swat had returned to their homes. The large number of off-camp IDPs and their scattered presence in various districts and disjointed displacement required a health response strategy capable of addressing the evolving operational challenges.

Employingknowledgefromprevious disasters in Pakistan since 2005, it was evident that without a common shared health cluster strategy, the response intervention carried out by 46 different health cluster partners would result in fragmentation, duplication and inefficiency. Against this backdrop, WHO led a participatory process of consultations engaging the government and health cluster partners. A comprehensive health cluster strategy guiding the IDPs' emergency health response interventions was developed, unanimously endorsed and disseminated for implementation. The strategy had a well defined operational scope covering the following 13 health response interventions. 


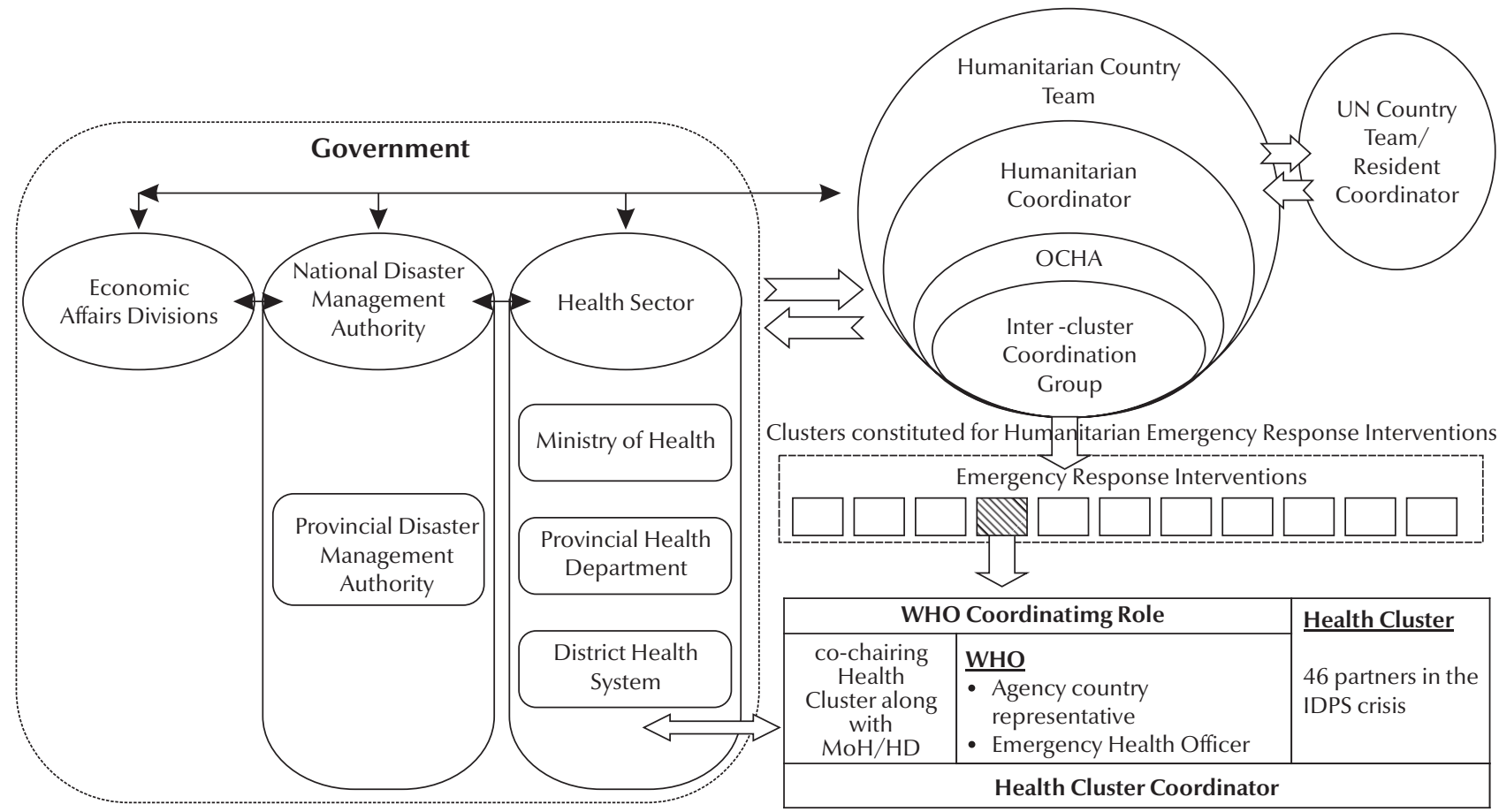

Figure 1 Humanitarian health response coordination framework in Pakistan (IDPs = internally displaced persons; OCHA = UN Office for Coordinating Humanitarian Affairs)

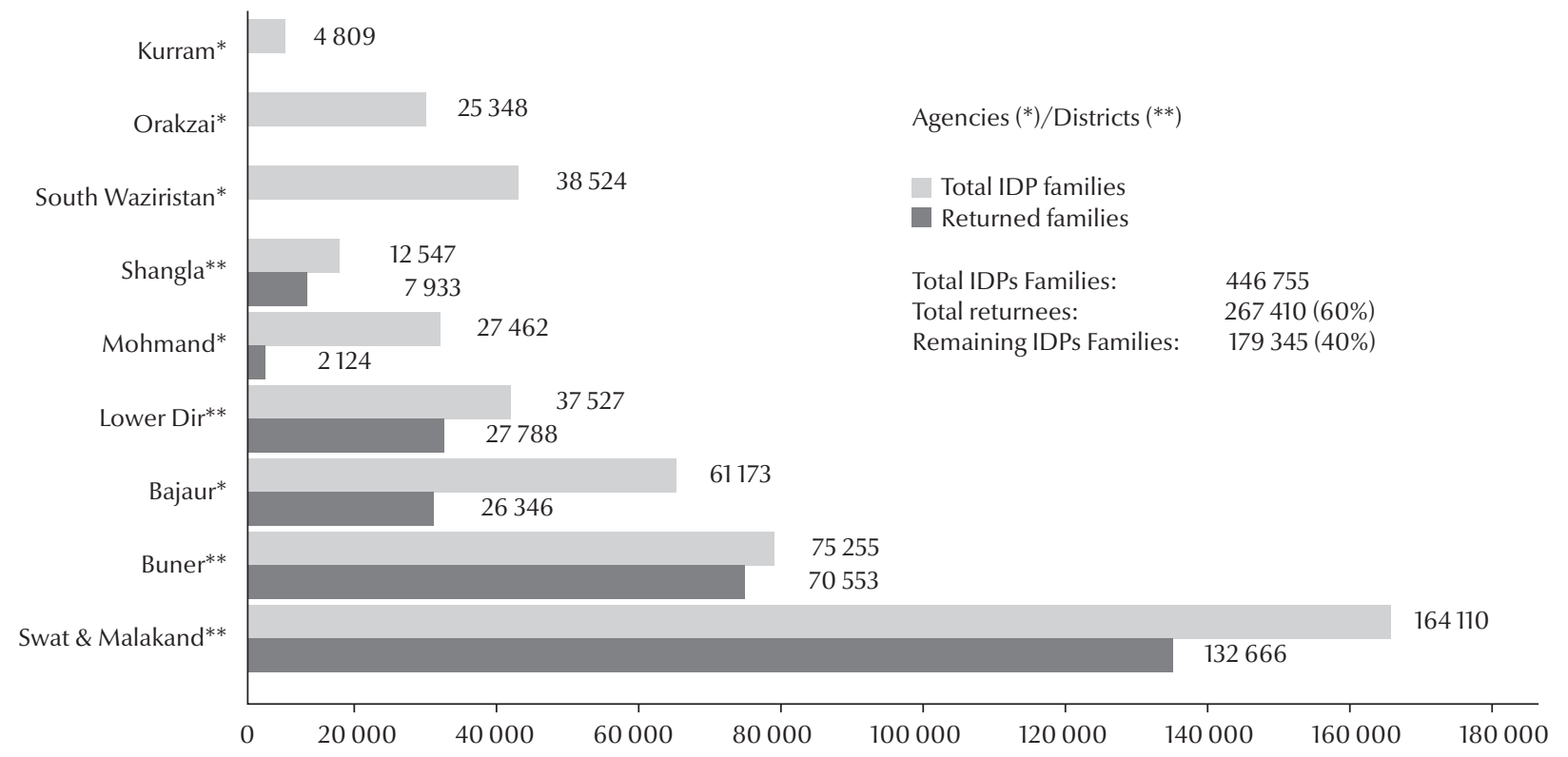

Figure 2 Total number of displaced families and returnees by area of origin from August 2008 to March 2010 (Source: Special Support Group (IDPs), PDMA (Provincial Disaster Management Authority) \& CAR (Commissioner Afghan Regugees) as of 22 March 2010)

Average family size: 7.3

IDPs = internally displaced persons 


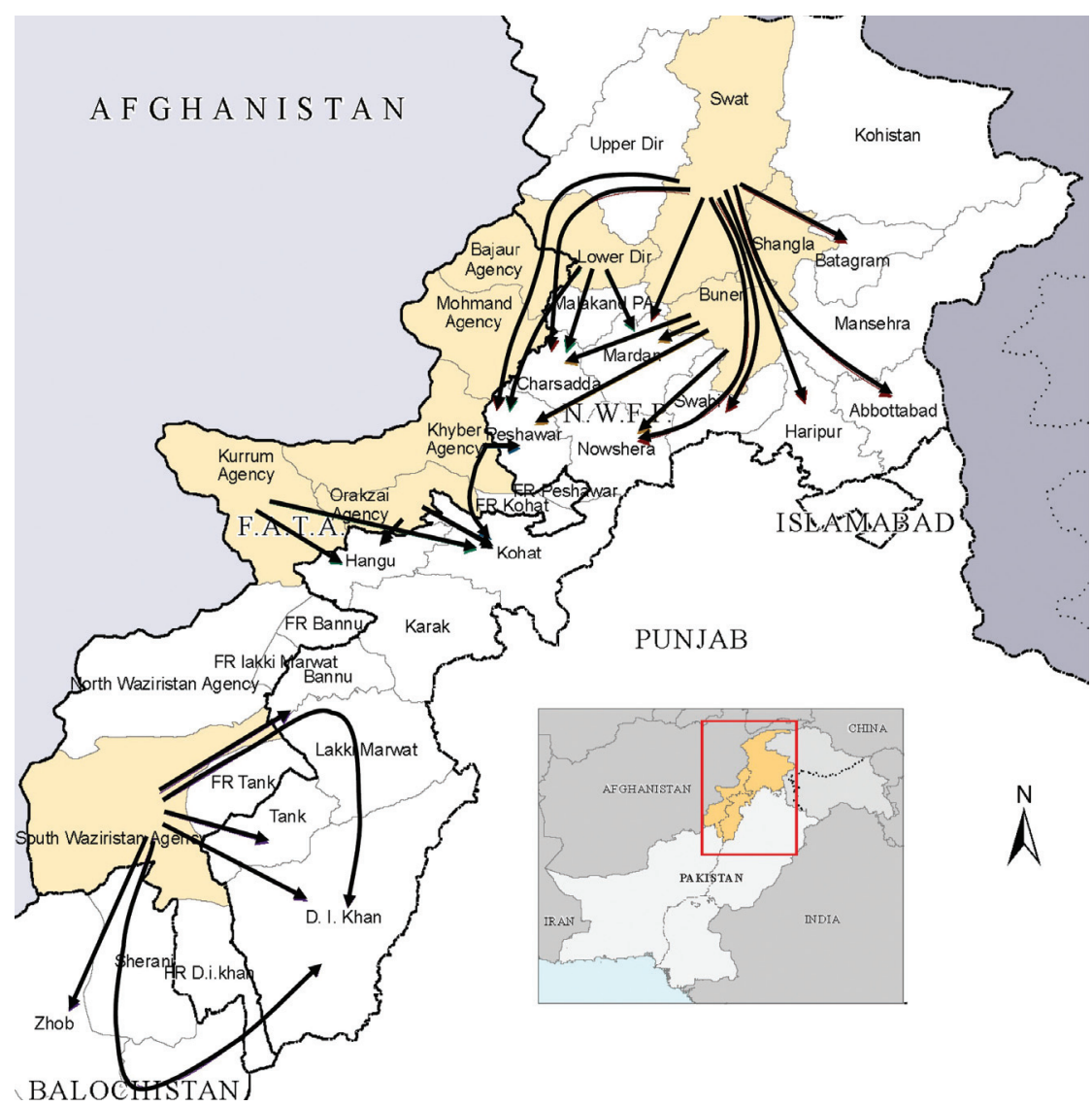

Figure 3 The movement of the internally displaced persons from the crisis affected agencies and districts of the Federally Administered Tribal Area and Khyber Pakhtunkhwa province

\section{Coordinating health action in crises}

Coordination was recognized as the overriding strategic function providing an appropriate mechanism for managinghealth interventions.WHO assigned a senior officer exclusively as cluster coordinator to facilitate the regular health cluster meetings at national and provincial levels, improve information sharing and joint planning, and rationalize resource mobilization, while effectively liaising with other clusters and OCHA to align health with the overall humanitarian response coordination.

\section{Initial rapid assessment}

In order to rationalize health response interventions and pave the way for need-based resource mobilization and action, the health cluster mandated the undertaking of rapid health assessment at the outset. Data were collected on the population's health status; their desired health needs and related perceptions. Similarly the health system infrastructure and the availability of human resources, medical supplies, equipment (including ambulances), logistics, for referral support were assessed as well as physical access to health facilities within the prevailing security environment. These data were the foundation for effective and need-based planning and enhanced the confidence of the health cluster in estimating the resources necessary for the response.

\section{Establishing the disease early warning system}

The disease early warning system (DEWS) is designed to rapidly detect the occurrence of 16 pre-selected diseases and conditions that would enable the health cluster to investigate and implement immediate control measures upon outbreak confirmation. The DEWS network covered all health facilities located in the crisis-affected region, while a WHO team in coordination with government health authorities prepared and widely shared a DEWS weekly bulletin. To avert the risk of outbreaks, the DEWS intervention was coupled with promotive and preventive health advocacy and the provision of safe drinking-water and sanitation. DEWS was sustained by the health authorities during the post-disaster rehabilitation and reconstruction period, rendering its functions, through $\mathrm{WHO}$ technical support, a permanent feature of the district health system.

\section{Controlling disease outbreaks}

The validated DEWS findings were classified as sporadic cases or evolving outbreaks, for which the relevant response was mobilized: intensive case management and timely dispatch of medicines and supplies, while maintaining the supply of safe drinking-water and sanitation, hygiene promotion and vector control. The three diseases that caused over $70 \%$ of all outbreaks were diarrhoeal diseases, measles and hepatitis (A \& E) viral infections, necessitating enhanced preparedness capacities. Disease control efforts also encompassed interventions for endemic priority communicable diseases such as tuberculosis and malaria supported by a network of laboratories backed up by the specialized National Institute of Health.

\section{Essential services package: enhancing quality and equity}

The fielding of skilled human resources and the application of best health response practices was a key component of the health cluster strategy that prompted the development of a set of institutional and service delivery guidelines and standards for all catchment area health facilities including referral districthospitals. The package stipulated promotive, preventive and curative care services and the provision of a defined 
Table 1 Essential operational guidelines and standards for the provision of primary health care services at different health facilities during emergencies

\begin{tabular}{|c|c|}
\hline \multicolumn{2}{|c|}{ Standards for health post/basic health unit } \\
\hline $\begin{array}{l}\text { - Structural standards for the establishment of a health facility/ } \\
\text { basic health unit } \\
\text { - Standards for the provision of essential health services in a } \\
\text { camp health post/basic health unit } \\
\text { - Essential medicines for a camp health post/basic health unit }\end{array}$ & $\begin{array}{l}\text { - Essential supplies and equipment for camp health post/basic } \\
\text { health unit } \\
\text { - Human resources for camp health post/basic health unit } \\
\text { - Recording and reporting tools } \\
\text { - Amenities required at the camp level }\end{array}$ \\
\hline \multicolumn{2}{|c|}{ Standards for mobile health clinic } \\
\hline $\begin{array}{l}\text { - Health services provided by a mobile health clinic } \\
\text { - Essential medicines for a mobile health clinic } \\
\text { - Essential supplies and equipment } \\
\text { - Human resources }\end{array}$ & $\begin{array}{l}\text { - Recording and reporting tools } \\
\text { - Standards of provision of an ambulance at a mobile health } \\
\text { clinic }\end{array}$ \\
\hline \multicolumn{2}{|c|}{ Standards for rural health centre } \\
\hline $\begin{array}{l}\text { - Structural standards for a rural health centre } \\
\text { - Standards for the provision of essential health services in a } \\
\text { rural health centre } \\
\text { - Essential medicines for a rural health centre } \\
\text { - Essential supplies and equipment for a rural health centre }\end{array}$ & $\begin{array}{l}\text { - Human resources } \\
\text { - Standards for the provision of an ambulance at a rural health } \\
\text { centre } \\
\text { - Recording and reporting tools }\end{array}$ \\
\hline \multicolumn{2}{|c|}{ General guidelines } \\
\hline $\begin{array}{l}\text { - Disease early warning system } \\
\text { - Rapid health assessment }\end{array}$ & $\begin{array}{l}\text { - Surveillance system } \\
\text { - Alert outbreak response and control }\end{array}$ \\
\hline \multicolumn{2}{|c|}{ Key communicable diseases } \\
\hline $\begin{array}{l}\text { - Acute watery diarrhoea } \\
\text { - Acute respiratory infections in children }\end{array}$ & $\begin{array}{l}\text { - Acute respiratory infection control in adults } \\
\text { - Malaria and tuberculosis }\end{array}$ \\
\hline \multicolumn{2}{|c|}{ Persons with disabilities } \\
\hline $\begin{array}{l}\text { - Health; promotive, preventive, medical care, rehabilitation } \\
\text { - Education; access to educational services }\end{array}$ & - Livelihood: access to livelihood opportunities \\
\hline \multicolumn{2}{|c|}{ Environmental health } \\
\hline $\begin{array}{l}\text {-Water facilities, access to water, water quality } \\
\text { - Excreta disposal }\end{array}$ & $\begin{array}{l}\text { - Water waste disposal and health care waste disposal } \\
\text { - Food storage and preparation }\end{array}$ \\
\hline
\end{tabular}

essential list of medicines, supplies and equipment as well as the deployment of human resources having the necessary skills for effective health response.

Table 1 illustrates the salient tasks for which specific operational guidelines and standards were set. They have induced uniformity, established minimal quality standards and enhanced the effectiveness of the implementation process.

\section{Mass vaccinations}

Mass vaccination of target child cohorts was a priority component of the health cluster strategy. During the crisis most children lost access to routine immunization services. This was compounded by the departure of a significant number of the health workforce for security reasons. Following the migration of the
IDPs, children between six months and 13 years were vaccinated against measles, while the under-fives were vaccinated against polio. Moreover, the backlog in routine immunization services was covered to control the risk of vaccine-preventable diseases. Likewise, tetanus toxoid vaccination was offered to all pregnant women. These vaccinations were planned and carried out by the government with UNICEF and WHO technical assistance and with the active support of all health partners.

\section{Maternal, neonatal and child health}

The delivery of maternal, neonatal and child health services including reproductive health and family planning constituted a primary health cluster strategy pillar and a fundamental element of the essential health services package. The health workforce necessary to deliver maternal, neonatal and child health services was standardized with the intention to field female care providers in all health facilities. These standards were to cater for female care seekers who desired to be attended by female care providers while facilitating access to basic and comprehensive emergency obstetric and neonatal care services.

\section{Nutrition surveillance}

Health cluster partners integrated nutrition surveillance into the health cluster strategy, linked it operationally with nutrition cluster operations and aligned it with DEWS implementation. Accordingly, nutrition surveillance and the management of severe child malnutrition was placed in the WHO 
comparative advantage domain where the organization has better capacity to engage relative to other partners. These interventions contributed to child survival and largely mitigated the risk of childhood mortality and morbidity.

\section{Health promotion and education: community action for health}

Displaced communities were exposed to unhealthy environmental conditions resulting from the risk of unsafe drinking-water, poor hygiene and sanitation, crowded makeshift shelters and deficiencies in food safety practices. Health promotion and education interventions were carried out as an integral component of the health cluster strategy at all service delivery outlets and through women's focal group sessions promoting hand-washing, home health care practices and improved care-seeking behaviour. To consolidate this process, WHO introduced the "Bangle Health Education" initiative for mothers residing in the largest IDP camp. Colourful bangles, commonly worn by rural women, were distributed when a group of mothers successfully completed a health education package, as a token of their participation and learning, facilitating the dissemination pace and acceptance rate of these messages.

\section{Procurement, supply and management of essential medicines}

This important strategic component facilitated the setting of guidelines for acceptable pharmaceutical donation, procurement, warehousing, stockpiling and distribution of essential life-saving medicines and supplies to which substantial humanitarian health resources were assigned. Prequalification criteria and quality control measures were introduced by WHO covering all medicines, and a committee coordinated their acquisition.

The use of WHO-managed grants earmarked for the IDPs' health response interventions during 2008-09 ensured that over $50 \%$ of the resources were used for the procurement of essential medicines, medical equipment for hospital capacity-building and for lifesaving logistics (Figure 4).

The WHO logistic supply system database was introduced in order to control the entry of procured or donated supplies, facilitate the tracking of available stockpiles along with their shelf lives and maintain an inventory of the stocks released to the field. WHOprocured medicines were distributed to a large number of health cluster partners and government facilities, which depended primarily on this supply chain for their field operations.

\section{Safety of drinking-water supply and sanitation}

The regular supply of safe drinkingwater to disaster-affected populations was carried out by the Water, Sanitation and Hygiene(WASH) cluster. Similar arrangements were also pursued for the construction of sanitary latrines for the affected population, especially those residing in camps. WHO was technically assigned to monitor water by assessing the contamination and chlorination levels of supplied water provisions. To fulfil this vital function, WHO environmental officers closely liaised with government institutions and operated mobile testing kits to regularly check water chlorination, both at the source and at the users' end. Contamination of water sources with coliform bacteria, largely from shallow wells, was blocked through coordination with WASH to avert the risk of waterborne disease outbreaks. To enhance the use of sanitary latrines, the WASH cluster was advised to separate male and female toilets to encourage utilization and deploy sanitary workers to safeguard their cleanliness. A health education programme, promoting water safety and hygienic sanitation was implemented to reinforce the importance of these practices.

\section{Mental health and psychosocial support}

The IDPs were predisposed to a range of mental and psychological conditions,

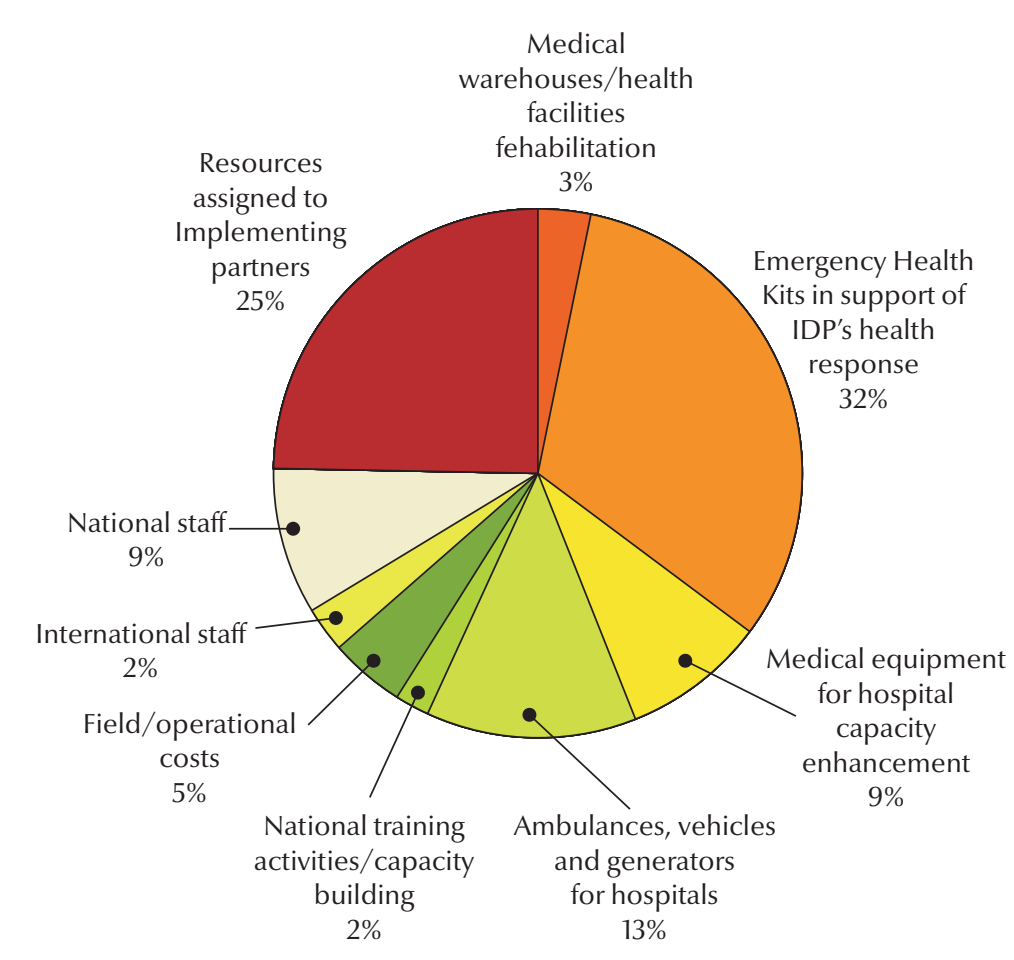

Figure 4 Use and expenditure analysis of WHO-managed grants earmarked for internally displaced populations during 2008-09 (IDPs = internally displaced persons) 
thus mental health was a key strategic priority for the health cluster. The Ministry of Health and the Khyber Pakhtunkhwa Provincial Health Department together with academic institutions and WHO mobilized a critical mass of mental health teams to serve in the disaster affected areas on a rotational basis. These professionals were also required to mainstream mental health into the primary health care network to sustain these services. A limited list of essential medicines was compiled and procured for eligible mental health cases. These interventions have offered mental health and psychosocial support services the prominence they deserve; a paradigm replacing the traditional neglect or focusing solely on therapeutic psychiatric care.

\section{Assisting persons with disabilities}

Among the IDPs, as in most humanitarian disasters, a substantial proportion of victims acquired disabilities, while others had disabilities before the disaster. During the crisis, displaced persons with disabilities were removed from their traditional supportive environment and confronted serious adaptation challenges. To address these impediments, $\mathrm{WHO}$, in collaboration with the government and other interested health cluster partners, initiated a programme offering rehabilitation and social support and offering access to specialized diagnostics facilities and opportunities for rehabilitation. These endeavours enabled many persons with disability to re-engage meaningfully in their social environment. To sustain the benefits of this intervention, the community-based rehabilitation programme, successfully implemented in the aftermath of the 2005 earthquake disaster, was also expanded to the IDPs.

\section{Discussion}

The immediate deterioration in access to essential health care and the rapid decline in the health status of affected populations resulting from natural or human-made disasters leads to the mobilization of humanitarian relief operations to mitigate suffering $[1,7,8]$. Commonly these interventions are marred by a lack of coordination with fragmentation, implementation gaps, duplication and parallel implementation [9]. These operational paradigms create inefficient distribution and use of scarce technical and material resources. The enormous challenges posed by the 2008-09 IDP crisis in Pakistan led to a serious societal disruption with grave health, economic and environmental consequences, exceeding the coping capacity of the population affected. The large number of off-camp IDPs, their sparse geographical distribution and phased displacement, with certain IDPs returning home while others were being simultaneously displaced required an immediate health response action guided by a shared operational strategy to address the acute health needs and avert impending morbidities and mortalities [10]. This vision was facilitated by the cluster approach first applied on a large scale during the 2005 south Asian earthquake, generating effective and cohesive partnerships among different national and international humanitarian organizations $[5,6]$. The health cluster strategy was designed to provide clearer avenues for effective coordination, joint planning, distribution of roles and responsibilities, resource mobilization and the creation of operational synergies, complementarities and shared accountability between partners. These capacities were unattainable without this shared strategic vision. The coordination component had the greatest bearing on the comprehensiveness and quality of emergency health response interventions and enabled the partners to work in unison for the delivery of relief operations.

In order to translate the 13 succinct operational components of the strategy into action, a functionally integrated essential service package was devised for the delivery of life-saving maternal, neonatal and child care services and other vital emergency health response interventions within the framework of primary health care and consistent with prevailing sociocultural norms of Pakistani society [11]. Accordingly, humanitarian health relief operations were channelled through the existing health services network from the newly established in-camp health facilities to the basic health units, rural health centres, sub-district hospitals and district hospitals, which received the bulk of life-threatening emergencies and clinically severe referral patient load. The strategy enabled federal, provincial and district health managers to monitor and guide performance closely and objectively, oversee the flow of the supply chain and appraise the results attained.

A key strategic component critical at the outset of the emergency was the initial rapid assessment of the health status of the affected population, the health system performance and the availability of human and supply resources, in addition to nutrition and safe water and sanitation aspects, both in the crisis-affected districts and in the districts hosting IDPs. The evidence generated was immediately used to revitalize primary health care services, enhancing hospital capacities in essential medicines, supplies and equipment and other structural and competency-related operational priorities [12]. Essential medicines and supplies constituted the most costintensive strategic component, and the health cluster partners recognized the value of using a common procurement and supply system managed by WHO for greater economies of scale, quality and efficiency [13].

To avert a second wave of death following the initial devastation, an epidemic control approach guided by DEWS was implemented [14]. The latter built on the surveillance of 16 critical notifiable diseases and conditions allowing for prompt investigation 
of all reported alerts, while the relevant disease control interventions were set in motion. Contrary to earlier reports underrating the effectiveness of disaster training for health care workers, the training on DEWS was effective in averting and controlling imminent epidemics among IDPs and their hosting communities [15]. Our observation is corroborated by an earlier experience related to health workers' training on essential surgical skills-emergency maternal and child health following the 2005 earthquake, with tangible improvements in maternal, neonatal and child health outcomes [16]. This experience illustrates the importance of across-cluster collaboration. These efforts were supplemented by expanding routine immunization activities and campaigns to promote awareness of health and nutrition, which were sustained throughout the relief operation.

The essential health care package implied the implementation of a range of primary health care services of a promotive, preventive, curative and rehabilitative nature defined for each level of care. The package included the provision of a standard list of life-saving medicines, supplies and equipment as well as the deployment of a minimum number of qualified human resources possessing the necessary skills for the job in hand. This has created a shared commitment to collectively meet the terms of an acceptable quality threshold for service delivery. Maternal, neonatal and child health including reproductive health and family planning was a central pillar of this essential package. Accordingly, women requiring emergency referral support were accessing comprehensive emergency obstetric and neonatal care facilities organized in district hospitals with tangible maternal and newborn survival outcomes, thus transforming the prevailing traditional fatalistic perception about maternal and neonatal death into a purposeful care-seeking practice. The health cluster strategy also emphasized extending healthresponseinterventionstoinclude secondary prevention and treatment of chronic noncommunicable diseases, care of persons with disabilities and the provision of mental health and psychosocial support, conditions often missed from the ambit of emergency health response interventions [17-19].

Contrary to high level strategies that cannot be drilled down to the operational level, the health cluster strategy was an actionable tool, resolving key challenges often faced during disasters and creating opportunities for cooperation, effective communication, collective efforts for health system strengthening and shared compliance with set operational, technical, organizational and logistical norms and standards. It ensured the necessary access to life-saving services. The availability and prompt deployment of a qualified national health workforce has characterized all subsequent Pakistani emergency health response interventions, an asset that has effectively contributed to the success of these humanitarian endeavours. This national capacity should be harnessed in the future to promote greater self-reliance in emergency preparedness at national, provincial, district and community levels with special focus on the safety of health facilities and strengthening the capacity of the health system.

To strengthen the capacity of this strategy in improving health response outcomes and attending to the unresolved gaps; humanitarian partners have to adopt the necessary technical and managerial tools that would enhance the outcome and impact of these strategic interventions. To strengthen the level of accountability, an outcome and impact assessment monitoring system need to be established. The latter has to be able to respond to life-saving needs; provide effective coverage and access to essential services with rational geographical distribution; apply key health indicators to monitor progress; define expected attainable results; promote gender equity in the response action; recognize the perceived needs of the affected population; and inculcate disaster risk mitigation. These imperatives should be put into operation to enable an objective evaluation of the Pakistan experience and allow its subsequent replication in similar settings.

The recently established National Centre for Health Emergency Preparedness and Response by the Ministry of Health in Islamabad with WHO technical support aims to provide leadership in developing a national health emergency mass casualty plan, scale up hospital response capacity and organize the development of a health workforce possessing the required managerial and technical competencies to respond effectively to future disasters following the parameters set by the health cluster strategy. The successful implementation of the strategy has generated a unity of purpose, improved the quality and effectiveness of health interventions and strengthened the cooperation and coordination between the national and international partners engaged in this complex humanitarian endeavour. The future application of this strategy would constitute a major asset in managing disasters regardless of the size of the hazard and level of population vulnerability.

\section{Acknowledgement}

The authors wish to acknowledge the contribution of the UN Office for Coordinating Humanitarian Affairs (OCHA) for providing updated information regarding the internally displaced families and their movement and returning trends. 


\section{References}

1. Health action in relation to crises and disasters, with particular emphasis on the earthquakes and tsunamis of 26 December 2004. Geneva, World Health Organization, 2005 (WHA58.1).

2. Chan EY, Kim JJ, Characteristics and health outcomes of internally displaced population in unofficial rural self-settled camps after the 2005 Kashmir, Pakistan earthquake. European Journal of Emergency Medicine, 2010, 17(3):136-141.

3. Sullivan KM, Hossain SM. Earthquake mortality in Pakistan: Disasters, 2010, 34(1):176-183.

4. Bile KM, Hafeez A. Crisis in the Swat Valley of Pakistan: need for international action. Lancet, 2009, 374(9683):23.

5. Moszynski P. Cluster approach improves provision of disaster aid, says WHO. British Medical Journal, 2008, 337:a1571.

6. Health cluster guide: a practical guide for country-level implementation of the health cluster. Geneva, IASC Global Health Cluster, World Health Organization, 2009.

7. Sheikh IA, Musani A. Emergency preparedness and humanitarian action: the research deficit Eastern Mediterranean Perspective. Eastern Mediterranean Health Journal, 2006, 12(2 Suppl.):554-563.

8. Arnold JL. Risk and risk assessment in health emergence management. Prehospital and Disaster Medicine, 2005, 20(3):143-154.

9. Bagchi $\mathrm{K}$ et al. Nutrition in humanitarian crisis. Eastern Mediterranean Health Journal, 2004, 10(6):747-53.

10. Shover $\mathrm{H}$. Understanding the chain of communication during a disaster. Perspectives in Psychiatric Care, 2007, 43(1):4-14.

11. Miller AC, Arquilla B. Disasters, women's health, and conservative society: working in Pakistan with the Turkish Red Crescent following the South Asian Earthquake. Prehospital and Disaster Medicine, 2007, 22(4):274-275.

12. Hsu EB et al. Healthcare worker competencies for disaster training. BMCMedical Education, 2006, 6:19.

13. Molina SL, Figge HL. Protecting the pharmaceutical supply chain. Ensuring an unbroken supply of pharmaceuticals can save lives during times of disaster. Health Management and Technology, 2008, 29(8):20-22.

14. Watson JT, Gayer M, Connolly MA. Epidemics after natural disasters. Emerging Infectious Diseases, 2007, 13(1):1-5.

15. Williams J, Nocera M, Casteel C. The effectiveness of disaster training for the health care workers: a systematic review. Annals of Emergency Medicine, 2008, 52(3):211-222.

16. Assad $\mathrm{H}$ et al. Emergency maternal and child health training courses and advocacy to achieve Millennium Development Goals in a poorly resourced country and opportunities. Journal of Pakistan Medical Association, 2009, 59(4):243-246.

17. Ruzek Jl et al. Integration of disaster mental health services with emergency medicine. Prehospital and Disaster Medicine, 2004, 19(1):46-53.

18. Goyet CV. Health lessons learned from the recent earthquakes and tsunami in Asia. Prehospital and Disaster Medicine, 2007, 22(1):15-21.

19. Chan EY, Gao Y, Griffiths SM. Literature review of health impact post-earthquakes in China 1906-2007. Journal of Public Health, 2010, 32(1):52-61. 